\title{
MULTISCALE DOCUMENTATION AND MONITORING OF L'AQUILA HISTORICAL CENTRE USING UAV PHOTOGRAMMETRY
}

\author{
D. Dominici ${ }^{\text {a }}$, M. Alicandro ${ }^{\text {a }}$, E. Rosciano $^{\text {b }}$, V. Massimi $^{\text {a }}$, \\ ${ }^{a}$ University of L'Aquila - Department of Civil, Construction-Architectural and Environmental Engineering - Laboratory of \\ Geomatic Afcea - Via Gronchi 18 - L'Aquila - 67100 - Italy \\ ${ }^{\mathrm{b}}$ ASI - Italian Space Agency - Matera Space Center - Contrada Terlecchia - Matera - 75100 - Italy
}

\section{Commission VI, WG VI/4}

KEY WORDS: Documentation, Geomatics, Historical Centre, Photogrammetry, UAV

\begin{abstract}
:
Nowadays geomatic techniques can guarantee not only a precise and accurate survey for the documentation of our historical heritage but also a solution to monitor its behaviour over time after, for example, a catastrophic event (earthquakes, landslides, ecc). Europe is trying to move towards harmonized actions to store information on cultural heritage (MIBAC with the ICCS forms, English heritage with the MIDAS scheme, etc) but it would be important to provide standardized methods in order to perform measuring operations to collect certified metric data. The final result could be a database to support the entire management of the cultural heritage and also a checklist of "what to do" and "when to do it". The wide range of geomatic techniques provides many solutions to acquire, to organize and to manage data at a multiscale level: high resolution satellite images can provide information in a short time during the "early emergency" while UAV photogrammetry and laser scanning can provide digital high resolution 3D models of buildings, ortophotos of roofs and facades and so on. This paper presents some multiscale survey case studies using UAV photogrammetry: from a minor historical village (Aielli) to the centre of L'Aquila (Santa Maria di Collemaggio Church) from the post-emergency to now. This choice has been taken not only to present how geomatics is an effective science for modelling but also to present a complete and reliable way to perform conservation and/or restoration through precise monitoring techniques, as shown in the third case study.
\end{abstract}

\section{INTRODUCTION}

Cultural heritage conservation concerns:

- the maintenance of objects and architecture in their current state in order to preserve the authenticity, the materials and the quality;

- the monitoring in order to prevent structural problems due to time or to disasters and to adopt the best techniques to go through restoration interventions (Remondino, 2016).

Since the cultural heritage preservation covers many fields of research, a combination of scientific, historical and cultural knowledge and experience of building conservation would be essential. An attempt to perform this protocol has been made in 1972, when an Unesco Convention established that States Parties should protect and mantain their own cultural and environmental heritage through effective management and monitoring systems to ensure protection for present and future generation (UNESCO, 1972). At the same time, many studies have tried to compare the different existing methodologies to draw some conclusions about the best practice and an optimal procedure (Kioussi et al., 2011). Even in (UNESCO/ICCROM/ICOMOS/IUCN, 2013) four main actions are defined to guarantee the optimal documentation and conservation of heritage:

1. Preliminary stage;

2. Data/Information acquisition;

3. Evaluation of the current status and/or artistic value;

4. Development of the proposal

The geomatics field regards the second step of this important chain since the wide range of the offered solutions can guarantee not only precise and accurate surveys but also a powerful way to monitor displacements and deformations over time after, for example, a catastrophic event (earthquakes, landslides, ecc). Geomatics can offer a sinergy between their several techniques and can deal with the cultural heritage in a very reliable way. One of the best way to get a synergy is the multiscale approach from high resolution satellite images for the "early emergency" to UAV photogrammetry and laser scanning for digital high resolution 3D models of buildings, ortophotos of roofs, facades and so on.

This paper focuses on the description of three case studies using UAV photogrammetry at different scales to present how geomatics is not only an effective science for modelling but also a complete and reliable way to perform conservation and/or restoration through precise monitoring techniques, as shown in the third case study.

\section{UAV PHOTOGRAMMETRY CASE STUDIES}

\subsection{Minor Historical Centre}

The first case study involves a survey of the urban centre of Aielli (AQ), a typical Italian small village. Several aspects are analysed in order to support a future sustainable requalification and restoration of the entire village. The centre is characterized by a medieval village in the north, while the ruins of the old village, destroyed by the earthquake of 1915, also subject of survey (Figure 1), are located in the north-west area (Institutional site of Avezzano, 2017). 


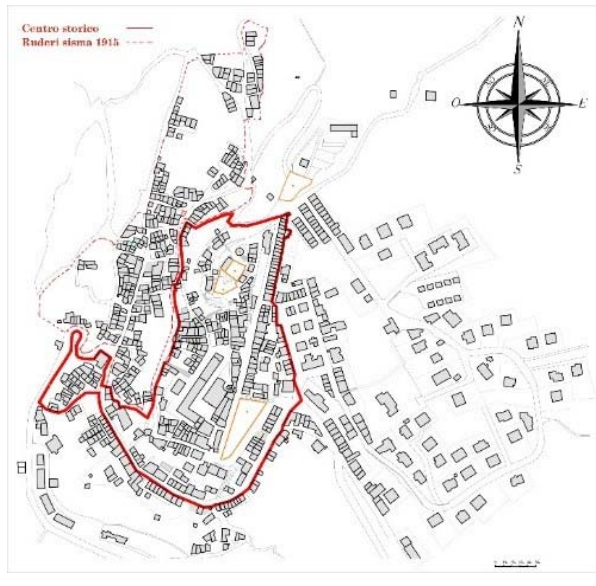

Figure 1. Area of interest

A multi-rotor Flynovex equipped with a Sony alpha 6000 camera (Figure 2) has been used in order to carry out the survey. The choice of this type of UAV and equipment stems from other tests performed in different case studies during the post-earthquake of L'Aquila in 2009 (Dominici et al, 2016). The evaluation has been made according with some technical aspects, in particular the payload of the camera and a good stability of the vehicle during the acquisition phase. Table 3 shows the main characteristics of UAV and of the optical sensor.

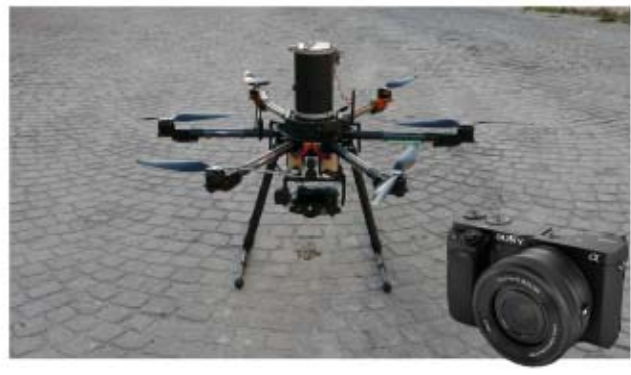

Figure 2. Type of UAV and technical specs of the camera.

\begin{tabular}{|c|c|c|c|}
\hline \multirow{2}{*}{ Type of $U A V$} & & & \multirow{2}{*}{$\frac{\text { Mini-UAV }}{\text { Hexa-copter }}$} \\
\hline & & & \\
\hline \multirow{7}{*}{$\begin{array}{l}\text { Optical } \\
\text { Sensor }\end{array}$} & \multicolumn{2}{|c|}{ Camera } & Sony alpha \\
\hline & \multicolumn{2}{|c|}{ Resolution } & $24 M P$ \\
\hline & \multicolumn{2}{|c|}{ Focal length } & $16 \mathrm{~mm}$ \\
\hline & \multirow{2}{*}{$\begin{array}{c}\text { Sensor } \\
\text { dimensions }\end{array}$} & width & $24 \mathrm{~mm}$ \\
\hline & & height & $16 \mathrm{~mm}$ \\
\hline & \multicolumn{2}{|c|}{ Pixel dimension } & $4.3 \mu \mathrm{m}$ \\
\hline & \multicolumn{2}{|c|}{ Weight } & $345 \mathrm{~g}$ \\
\hline
\end{tabular}

Table 3. Type of UAV and technical specs of the camera.

In the following, the main steps to obtain a metric 3D model are presented: the flight planning, the data acquisition and the final step of elaboration.

\subsubsection{Flight Planning}

The flight planning includes all activities aimed to define the waypoints from which the UAV will take the picture during the acquisition phase.

The flight planning has been generated with a dedicated planning software "FlyTop Manager", released with the UAV. Starting from the knowledge of the relationships that exist between the characteristics of the sensor (focal length and sensor size), the flight altitude and the Ground Sample Distance (GSD), the software implements the algorithm to determine the flight height according to the following equation:

\section{Errore. Non si possono creare oggetti dalla modifica di} codici di campo.

Where

$$
\begin{aligned}
& c=\text { camera focal length } \\
& \mathrm{H}=\text { flight altitude or distance of the object } \\
& \mathrm{d}_{\text {pix }}=\text { pixel dimension } \\
& \text { GSD = Ground Distance Sample. }
\end{aligned}
$$

Imposing the GSD, which defines the medium scale of the photograms (Kraus, 1994), equal to $2 \mathrm{~cm}$, a flight altitude of about $75 \mathrm{~m}$ has been obtained.

After the flight altitude has been established, in order to determine the number of picture, a high overlap of $80 \%$ between images has been imposed to guarantee the 3D vision and to avoid the occlusion problems due to the shadow and the nadiral acquisition (Brito, 2000), peculiar of the UAV photogrammetry (Nex and Remondino, 2014). A second flight has been planned with an oblique acquisition of $10^{\circ}$ to reduce this last problem. The oblique acquisition affects negatively the GSD value (Höhle, 2008), but, in our case study, the maximum variation was $0.4 \mathrm{~cm}$. Considering all the previous quantities, 143 waypoints have been planned for each flight.

\subsubsection{Acquisition phase}

After the creation of an accurate flight planning, the flights can be executed following the pre-imposed route to collect the images for further elaboration. In addition, 35 natural Ground Control Points (GCPs) have been collected (Figure 4) for georeferencing and for scaling the final model. The GCPs have been measured with a Leica GNSS receiver in Real Time Kinematic (RTK), obtaining the 3D WGS84 coordinates with about a centimetre precision

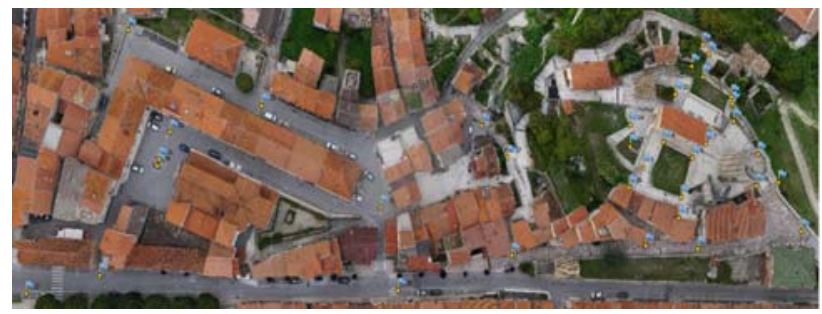

Figure 4. GCPs distribution.

\subsubsection{Data elaboration}

The data elaboration has been carried out using Agisoft Photoscan which allows to obtain the 3D model following the "Structure From Motion" workflow (Westoby et al., 2012) and the Dense Matching approach (Figure 5). 


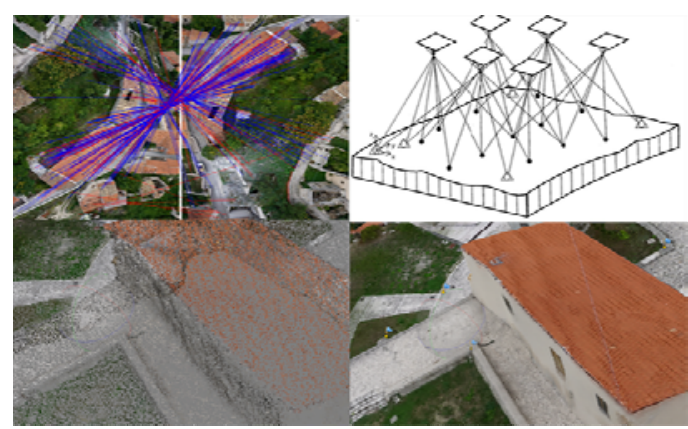

Figure 5. Principal step of elaboration data. a) Tie-points matching; b) bundle adjustment; c) Dense matching and d) texture.

First of all, a selection of the images has been realized to eliminate those ones with illumination or poor quality issues, reducing the number of picture to 258 .

Initially, the matching features allow to detect the tie-point between adjacent images using descriptors and detectors algorithm (Remondino, 2006).

Subsequently, bundle adjustment retrieves the camera position for all images and the interior orientation (calibration parameters) of the camera, allowing the generation of sparse 3D point clouds. Thanks to high number of tie-points, a statistical adjustment is implemented. The values of camera calibration can be achieved in an automatic way (Fraser, 1997) considering those values as variables in the resolution of the collinearity equations. Then, the insertion of 16 GCPs along with the tiepoints allows to georeference and to scale the 3D models and to refine the output of the bundle adjustment. The other collected points are used as Check Points (CPs) to compare the results with the "ground truth" as explained in the results section.

Once obtained the orientation parameters with dense matching algorithm (Agisoft Photoscan, 2011), a depth map is calculated in medium quality to reconstruct the dense cloud. Moreover, a moderate filter is imposed to remove the noise in the areas with few points, in particular in the green areas.

Finally, the mesh is created by using the arbitrary mode as method of reconstruction to extract detailed information on the facades of the building. The result is a 3D model, subsequently texturized.

\subsubsection{Results}

The main results of the processing phase are the georeferenced 3D models from which it is possible to extract several outputs (ortophoto and DEM -Figure 6 - section and prospect) useful to plan the future analysis of requalification.

In order to assess the bundle adjustment results, Table 7 contains the global residual values of the bundle adjustment.

As mentioned above, only 16 surveyed points are used as GCPs, while the other points are used as CPs to assess the quality of the results. It is possible to see that the GCPs residual is smaller with respect to the CPs ones. This is due to the high redundant adjustment's influence on GCPs coordinate values, which may induce an overestimation of the precision.

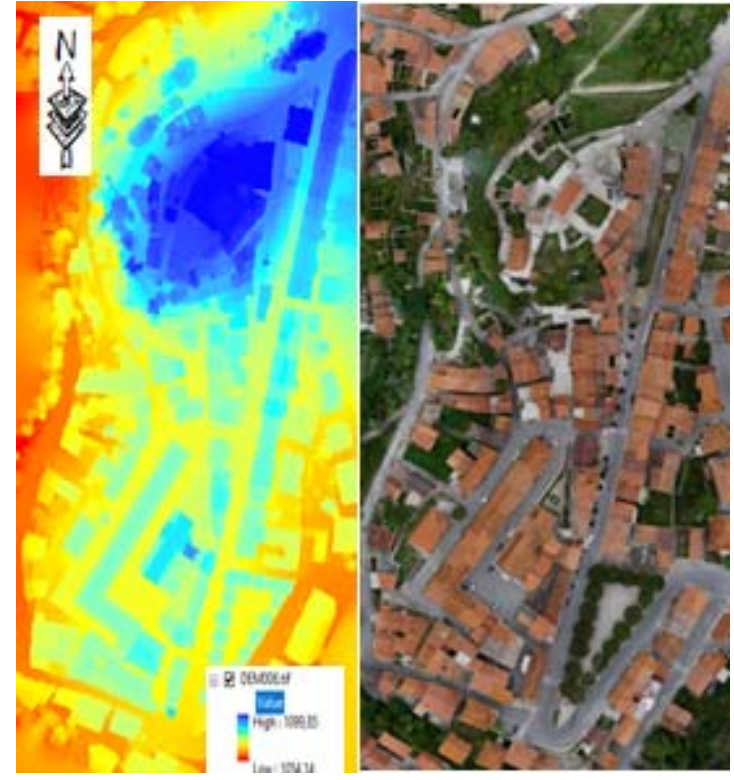

Figure 6. DEM and ortophoto.of Aielli.

\begin{tabular}{|c|c|c|}
\hline GCPs & Error (m) & Error (pix) \\
\hline 16 & 0.05 & 1.30 \\
\hline CPs & Error (m) & Error (pix) \\
\hline 19 & 0.09 & 1.42 \\
\hline
\end{tabular}

Table 7. Final residuals of the bundle adjustment.

\subsection{Santa Maria di Collemaggio Church}

The second case study regards the UAV photogrammetry survey of an important cultural heritage of L'Aquila, the church of Collemaggio. This case study is different from the first one because of the scale of acquisition, the photogrammetry acquisition method (terrestrial photogrammetry) and the extracted features. This survey has been conducted in 2012 in collaboration with Aermatica S.p.a. with a specific quadcopter Anteos A2-Mini/B, a stable UAV with large dimension (about 2 $\mathrm{m}$ of wingspan) equipped with a compact Canon S100 camera ( Figure 8).

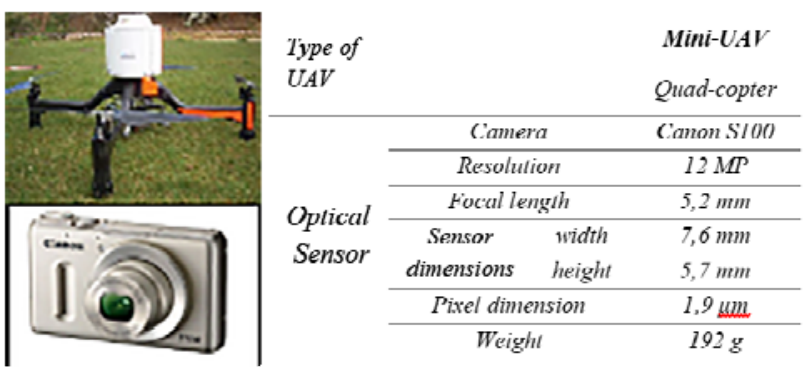

Figure 8. Mini-Anteos and camera specs.

The site is characterized by a large green park in front of the principal facade while a road is next to the side where the 'Holy Door' is located. The distance between the cliff and the church is of about $10 \mathrm{~m}$ (Figure 9). In this case study, the flight planning has been separated in two different project. 


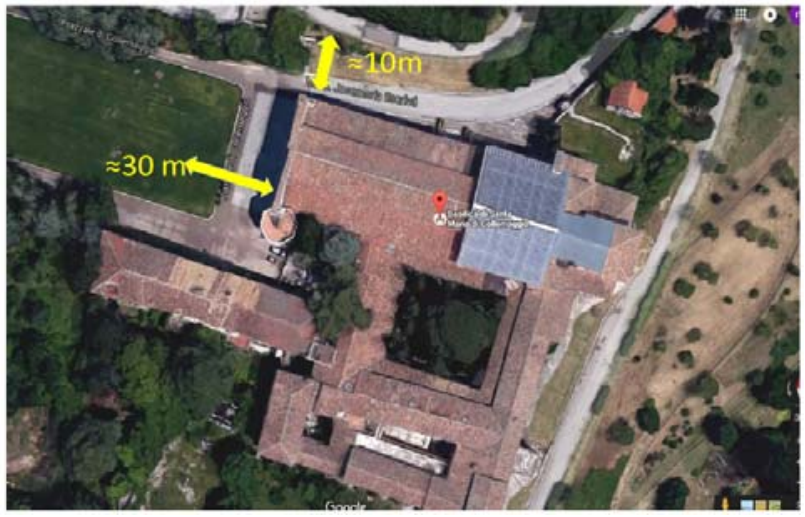

Figure 9. Top-view of the church.

\subsubsection{Flight planning}

Two flight have been planned with a vertical route and a horizontal acquisition to reconstruct the church facades. In this case study, due to the particular structure of the Anteos A2Mini/B, it is mandatory to apply a Field Of View (FOV) direction of $16,5^{\circ}$ with respect to the horizontal direction in order to exclude any part of the UAV in the photograms.

For the first flight, the distance of the UAV from the facades have been of $30 \mathrm{~m}$, knowing the camera parameters (focal length $=5,2 \mathrm{~mm}$ and sensor size $=7,6 \times 5,7 \mathrm{~mm}$ ) used to obtain a GSD equal to $1 \mathrm{~cm}$.

Applying the correction due to the oblique acquisition, the maximum and minimum variation of GSD is equal to $0.5 \mathrm{~cm}$. In order to limit the effect of the oblique image, it is generally necessary to increase the overlap between images and to improve their redundancy (Rupnik et al., 2014). Then, 14 waypoints are obtained imposing an overlap of $90 \%$.

For the second flight, the narrow distance of the façade is the main issue to plan a flight with the same parameters of the first flight. Imposing the $\mathrm{H}$ in equation (1), the GSD is equal to 0,36 $\mathrm{cm} \mathrm{cm}$ with $0,1 \mathrm{~cm}$ of variation for the oblique acquisition. 291 images are planned to cover the entire church.

\subsubsection{Data acquisition}

As in the previous case study, after the UAV acquisition, 52 natural GCPs easily identifiable and distributed on the entire structure have been measured in a local reference system. A TS30 Total Station has been used obtaining a precision of the coordinates values equal to a few millimetres. The local reference system has been measured with the GNSS technique in static mode in order to georeference the final model in WGS84.

\subsubsection{Elaboration step}

The high number of photograms has made necessary two different projects in Agisoft Photoscan to reconstruct the entire building. The elaboration has been conducted in high resolution to highlight the details of the church, the particular motif in correspondence to the doors and the rose windows. Nevertheless, it took about 24 hours to complete the whole elaboration steps with a PC station characterized by a $3.4 \mathrm{Ghz}$ Octa core processor with 16 GB of RAM. Finally, the two projects are merged by using of GCPs.

\subsubsection{Results}

In Figure 10 and Figure 11, the 3D model of the church of Collemaggio and some details are presented. A detailed geometrical analysis of the principal façade is discussed in the next section.

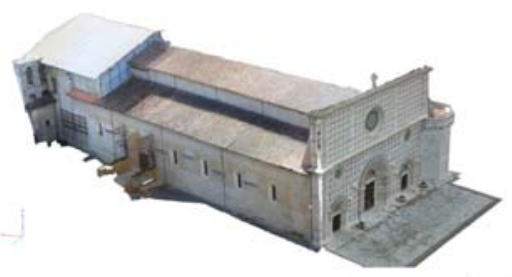

Figure 10.3D model of Collemaggio church.
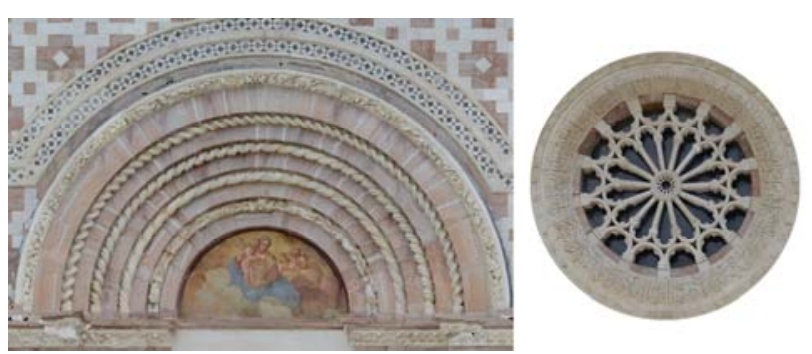

Figure 11. Reconstructed details of the principal façade.

Table 12 shows how the different GCPs and CPs distributions (Figure 13) don't affect the final precision of the model.

\begin{tabular}{|c|c|c|}
\hline Case 1 & GCPs & CPs \\
\hline$\#$ & 7 & 45 \\
\hline Res. (m) & 0.036 & 0.062 \\
\hline Res. (pix) & 1.36 & 1.40 \\
\hline Case 2 & GCPs & CPs \\
\hline$\#$ & 11 & 41 \\
\hline Res. (m) & 0.032 & 0.039 \\
\hline Res. (pix) & 1.32 & 1.41 \\
\hline Case 3 & GCP & CPs \\
\hline$\#$ & 20 & 32 \\
\hline Res. (m) & 0.027 & 0.047 \\
\hline Res. (pix) & 1.36 & 1.41 \\
\hline
\end{tabular}

Table 12. Residual values for different distribution of GCPs and CPs in the bundle adjustment.

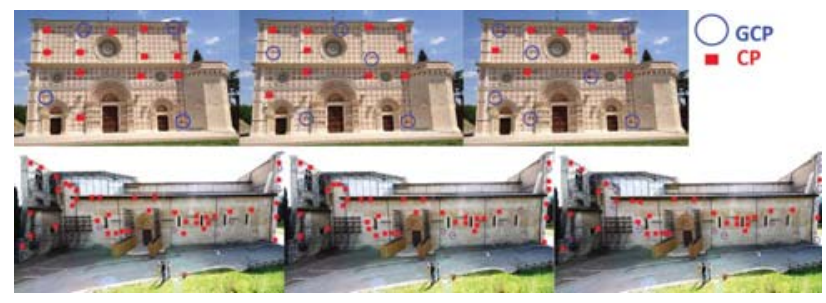

Figure 13. Different distributions of GCPs and CPs. From the left to the right: Case 1, 2 and 3 (see Table 12)

\subsection{The main Collemaggio façade: a first attempt of using} UAV photogrammetry for building monitoring

The third case study completes the multiscale analysis. In this subchapter, an example of how geomatics could be helpful in a 
post-emergency phase is remarked. Indeed, since monitoring is one of the best way to preserve, it is important to find a reliable technique to guarantee not only precision and accuracy but also safety for technicians. The UAV technique is the best one in terms of the previous issues. The analysis of the deformations on buildings and the measure of verticality can be obtained using a total station which can guarantee huge precision and accuracy (less than $1 \mathrm{~mm}$ ). A strong network has to be designed and the measure has to be performed using the classical methods to avoid systematic and random errors. This case study tests the UAV photogrammetry for the building monitoring.

\subsubsection{Step 1: data acquisition}

As described in chapter 2.2, a 3D model of the entire Collemaggio church has been generated by using 291 photograms and 52 GCPs. The final RMS of the point clouds is equal to $3 \mathrm{~cm}$. A comparison with the reliable total station survey has been performed to test the accuracy. 63 points are measured using a Leica TS30 total station, according to a regular scheme (Figure 14). No targets have been used since the façade has a particular geometrical motif. 26 vertical lines and 7 horizontal lines of points have been measured. The network measured from 3 different stations has been adjusted with Star*Net achieving an average of $0.3 \mathrm{~mm}$ precision.
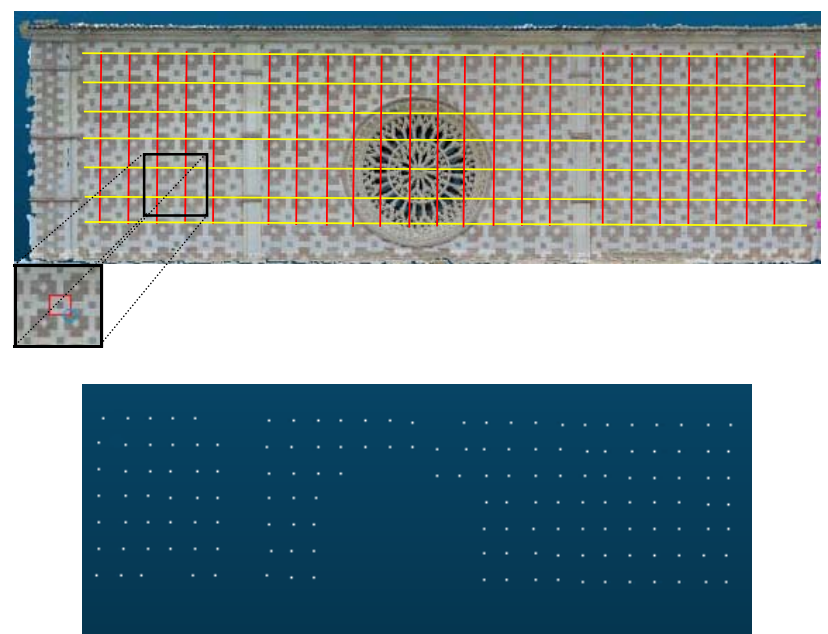

Figure 14. Points surveyed on the façade using the Leica TS30 total station.

At the same time, the facade points cloud from Agisoft Photoscan has been extracted from the entire 3D model. The aim of the study is to compare the two clouds to check the photogrammetry cloud accuracy.

\subsubsection{Step 2: comparison of the two techniques}

Discrete data from total station and continuous data from Agisoft have been imported into Cloud Compare, a dedicated software for analysing the points cloud (millions of points). This software has been chosen as implements a powerful "change detection" algorithm for the time series analysis of the points cloud. For the aim of this paper, this algorithm will be used to check the accuracy of the photogrammetry cloud. Since the two models are computed in different reference systems, the first step has been the registration of the UAV cloud in the "discrete" cloud system. This operation has been performed with 8 points selected in the two models. Figure 15 shows the final overlap and
Table 16 both the final alignment and the commons points RMS errors.

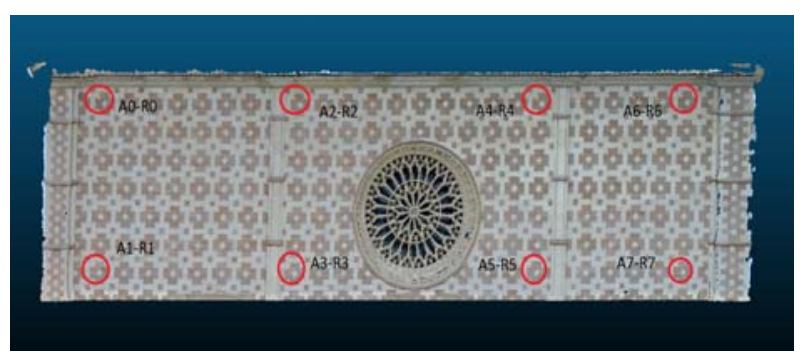

Figure 15. Overlap between the reference and the photogrammetric cloud.

\begin{tabular}{|l|l|}
\hline \multicolumn{2}{|l|}{ Final RMS: $0.0063 \mathrm{~m}$} \\
\hline A0 - R0 & $0.0060 \mathrm{~m}$ \\
\hline A1 - R1 & $0.0059 \mathrm{~m}$ \\
\hline A2 - R2 & $0.0077 \mathrm{~m}$ \\
\hline A3 - R3 & $0.0052 \mathrm{~m}$ \\
\hline A4 - R4 & $0.0061 \mathrm{~m}$ \\
\hline A5 - R5 & $0.0073 \mathrm{~m}$ \\
\hline A6 - R6 & $0,0065 \mathrm{~m}$ \\
\hline A7 - R7 & $0,0057 \mathrm{~m}$ \\
\hline
\end{tabular}

Table 16. Final RMS from cloud alignment.

\subsubsection{Step 3: the "change detection"}

The comparison of point clouds is performed basically in two ways:

1. Considering displacements between corresponding points (Monserrat and Crosetto, 2008);

2. Measuring distances between clouds as in the change detection technique (Rosser et al., 2005) based on surface local direction normal lines.

A plane surface of comparison is preferred in particular in the second methodology. This is the main task of the $\mathrm{M} 3 \mathrm{C} 2$ (Multiscale Model to Model Cloud Comparison). The main advantages of this algorithm are (Lague et al., 2013):

- $\quad$ the use of points instead of meshes;

- the computation of local distances between clouds to account for variations in surface orientations;

- the use of a "confidence interval" which takes into account the input error registration, the position uncertainty due to the instrument used and the surface roughness of the clouds involved in the comparison.

The analysis is performed on the so-called core points (Brodu et al., 2012) placed in an area called "Region Of Interest". The neighbour points are fitted with a plane and a normal line for each of these planes is estimated.

The M3C2 algorithm acts in two steps:

1. Generation of the normal lines (one for each core point) to the centre of a circle of a certain diameter (normal scale). The standard deviation of the distance of the points from the interpolated plane could be a measure of the surface roughness; 
2. Calculation of the distance $\mathrm{L}_{\mathrm{M} 3 \mathrm{C} 2}$ along the normal within a cylinder with the normal scale as diameter connecting the clouds.

In the following description, the total station cloud will be the reference cloud while the photogrammetry one will be the compared cloud.

Figure 17. shows the geometrical scheme of the algorithm $\left(\mathrm{C}_{\mathrm{a}}\right.$ is the reference cloud while $\mathrm{C}_{b}$ is the compared cloud).

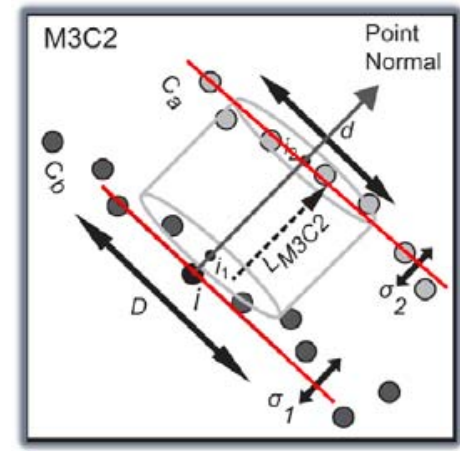

Figure 17. Geometrical scheme for the M3C2 algorithm.

The reference cloud has been selected as core points. A normal scale of $50 \mathrm{~cm}$ has been chosen to take into account a minimum overlap between the circles generated around every core point.

The $\mathrm{M} 3 \mathrm{C} 2$ algorithm on Cloud Compare gives several information as output: mean and standard deviation of the fit with a plane for the reference cloud (STD_cloud1) and the compared cloud (STD_cloud2) and the same for the $\mathrm{L}_{\mathrm{M} 3 \mathrm{C} 2}$ (M3C2 distance) as

Figure 18 shows.
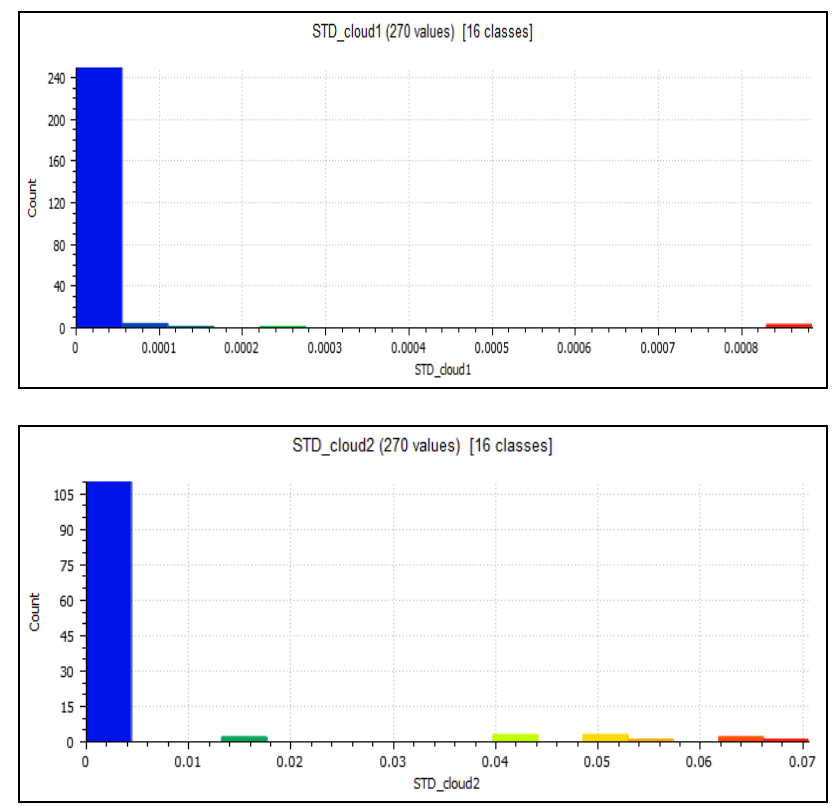

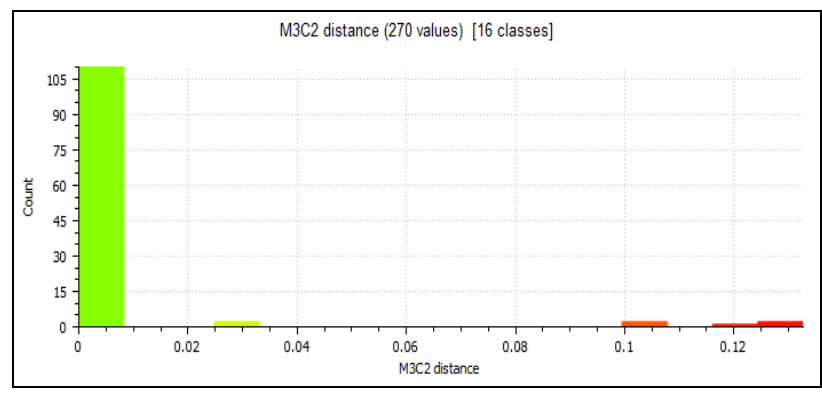

Figure 18. Standard deviations for the reference cloud, the photogrammetry cloud and results from the application of the M3C2 algorithm.

Table 19 shows the mean and standard deviation of the planes fitting the reference and the compare clouds. Finally, in the last row the mean and standard deviation of $\mathrm{L}_{\mathrm{M} 3 \mathrm{C} 2}$ distance are shown.

As plots show, the plane fitting the reference cloud has mean and standard deviation lower than the photogrammetry ones. This could be the consequence of the choice of the normal scale value with respect to the architectonic complexity of the façade, especially around the rose window. Probably, the same anomaly affects the $\mathrm{L}_{\mathrm{M} 3 \mathrm{C} 2}$ distance as the mean and standard deviation differ from one order of magnitude. As stated in section 2.3.1, comparing the two clouds could be an indicator of accuracy. In fact, the mean value of the $\mathrm{L}_{33 \mathrm{C} 2}$ distance is satisfactory but the large standard deviation has to be inspected. Nevertheless, the algorithm gives good results for rough surface (Lauge et al. 2013), the parameters have to be set up to deal with the architectonic complexity. This will be the authors future prospect.

Finally, it can note stated that this technique could not be used to perform a precise monitoring (a precision of less than $1 \mathrm{~mm}$ is required), but it could give a first response to evaluate the damages after a catastrophic event.

\begin{tabular}{|c|c|c|}
\hline & Mean (m) & $\begin{array}{c}\text { Standard } \\
\text { Deviation }(\mathrm{m})\end{array}$ \\
\hline STD1_cloud & 0.0001 & 0.0005 \\
\hline STD2_cloud & 0.0045 & 0.0014 \\
\hline LM3C2 & -0.0034 & 0.0106 \\
\hline
\end{tabular}

Table 19. Least square mean and standard deviation from the application of the $\mathrm{M} 3 \mathrm{C} 2$ algorithm.

\section{CONCLUSIONS}

The current paper provides a test of the UAV photogrammetry technique at different scales of research from the historical village of Aielli to the Basilica of Collemaggio which is a cultural heritage of primary importance. This particular choice stems from the role which nowadays the requalification and the reuse of the national heritage is assuming. In particular, this role is assumed mostly in the specific context of the inner area of the region Abruzzo where on April 2009 an earthquake affected the entire area. Moreover, this study offers the opportunity to propose and to experiment with the integration of new geomatic techniques and data acquisition methods with new forms of design for the sustainable restoration of historical centers and the repopulation of those areas.

This study is part of a broader research work which the "Geomatics group" in the University of L'Aquila is carrying forwards in the last years to ensure a sinergy between the 
different players in the reconstruction works starting from the richness of the italian historical centers. In this context, the results reported in the paper gives an important operating tool which may be offered to the public administrations and the citizens. The data are indeed supported with high precision and accuracy to be easily included in a georeferenced cartographic archive of the urban buildings with 3D modeling, ortophoto and DEM of the cultural heritage of primary importance. Moreover, they are reliable and ready to be used for a smart management of an urban database.

The research has been focused on a possible management strategy of the point clouds acquired from an UAV photogrammetry technique to control the displacements. This technique can be used after a definition of the geometrical characteristics of the building based on verticality and inclination checks. The experience gained by the group of the University of L'Aquila in the period after the earthquake and the results presented in this work demonstrate the utmost need of an archive of cultural heritage and urban buildings of the historical centers. This archive might be really important in the first evaluations of the hazard index for all the buildings of primary social and cultural importance. The future studies will be oriented towards the enrichment of information using other thermal and multispectral sensors and will be also focused on the building monitoring.

\section{REFERENCES}

Agisoft Photoscan Manual, 2011. www.agisoft.com.

Brito, J., 2000. Occlusion detection in digital images through bayesian networks. Int. Arch. Photogramm. Remote Sens. Vol. XXXIII, Part B3, pp. 101-108.

Brodu, N., Lague, D., 2012. 3D terrestrial lidar data classification of complex natural scenes using a multi-scale dimensionality criterion: applications in geomorphology. ISPRS Journal of Photogrammetry and Remote Sensing. 68, pp. 121134.

Dominici, D. et al., 2016. UAV photogrammetry in the postearthquake scenario: case studies in L'Aquila. Geomatics, Natural Hazards and Risk. pp. 1-17.

Fraser, C.S., 1997. Digital camera self-calibration. ISPRS Journal of Photogrammetry and Remote Sensing. 52, pp. 149159.

Höhle, J., 2008. Photogrammetric Measurements in Oblique Aerial Images. Photogramm. Fernerkund. Geoinformation pp. 7-14.

Institutional site of Avezzano, 2017. www.comune.avezzano.aq.it/pagina3914 il-terremoto.html.

(January, 27, 2017).

Kioussi, A. et al., 2011. Recommendations and strategies for the

establishment of a guideline for monument documentation harmonized with the existing european standards and codes. Geoinformatics CTU FCE, pp. 178-184.

Lague, D. et al., 2013. Accurate 3D comparison of complex topography with terrestrial laser scanner: Application to the Rangitikei canyon (N-Z). ISPRS Journal of Photogrammetry and Remote Sensing. 82, pp. 10-26.
Monserrat, O., Crosetto, M., 2008. Deformation measurement using terrestrial laser scanning data and 3D least square surface matching. ISPRS Journal of Photogrammetry and Remote Sensing. 63 (1), pp. 142-154.

Kraus, K., 1994. Fotogrammetria. Libreria universitaria Levrotto \& Bella, Torino. Vol.1.

Nex, F., Remondino, F., 2014. UAV for 3D mapping applications: a review. Appl. Geomat. 6, pp. 1-15.

Remondino, F., 2006. Detectors and descriptors for photogrammetric applications. Int. Arch. Photogramm. Remote Sens. Spat. Inf. Sci. 36, pp. 49-54.

Remondino et al., 2016. Geomatics for cultural heritage preservation. $\mathrm{http}: / / \mathrm{www} \cdot g i m-$ international.com/magazines/gim-international-february2016.pdf (March 2017).

Rosser, N.J. et al., 2005. Terrestrial laser scanning for monitoring the process of hard rock coastal cliff erosion. Quarterly J. of Eng. Geology and Hydrogeology. 38 (4), pp. 363-375.

Rupnik, E., Nex, F., Remondino, F., 2014. Oblique multicamera systems-orientation and dense matching issues. Int. Arch. Photogramm. Remote Sens. Spat. Inf. Sci. Vol. XL, 3/W1, pp. 107-114.

Westoby, M.J., Brasington, J., Glasser, N.F., Hambrey, M.J., Reynolds, J.M., 2012. "Structure-from-Motion" photogrammetry: A low-cost, effective tool for geoscience applications. Geomorphology 179, pp. 300-314.

UNESCO/ICCROM/ICOMOS/IUCN, 2013. Managing cultural world heritage. World Heritage Resource Manual.

UNESCO, 1972. Convenzione riguardante la protezione sul piano mondiale del patrimonio culturale e naturale. 